\title{
LA FUTURA CONSTITUCIÓN EUROPEA Y LA CARTA DE LOS DERECHOS FUNDAMENTALES DE LA UNIÓN EUROPEA DESDE IBEROAMÉRICA
}

\author{
Héctor GROS ESPIELL*
}

RESUMEN: El proceso en curso para la adopción de una Constitución Europea tiene una enorme trascendencia política y jurídica. Constituye asimismo un nuevo enfoque para encarar la cuestión de las integraciones regionales con universales proyecciones conceptuales. La Carta de Derechos Fundamentales de la Unión Europea, ya adoptada, pero que no tiene carácter convencional, al integrarse a la futura Constitución no sólo poseerá este carácter, sino que adquirirá un valor constitucional para la Unión Europea y para los Estados miembros.

ABSTRACT: The process of adoption of a European Constitution has an enormous political and legal transcendence. It constitutes a new focus to approaching the regional integration issues, with universal conceptual projections. The Charter of Fundamental Rights of the European Union, already adopted though without a conventional character, when being incorporated to the future Constitution, it will not only have that character, but it will acquire a constitutional value to the European Union and the Member States.

RÉSUMÉ: Le processus d'adoption d'une Constitution Européenne a une énorme transcendance politique et juridique, de même qu'il représente une nouvelle façon d'envisager le thème des intégrations régionaux à travers des proyections conceptuelles universelles. Quand la Charte des Droits Fondamentaux de l'Union Européenne — déjà adoptée mais sans caractère conventionnelle - soit incorporée à la future Constitution, elle en acquerirá un, ainsi qu'une valeur constitutionnelle tant pour la Union Européenne, que pour les Etats Membres.

* Profesor emérito de la Universidad de la República, Uruguay, y miembro del Comité Internacional de Bioética. 
SUMARIO: I. La futura Constitución Europea y la Carta de los Derechos Fundamentales de la Unión Europea vistos desde Iberoamérica. II. La futura Constitución Europea. III. La Carta de los Derechos Fundamentales de la Unión Europea. IV. Una visión iberoamericana de la Constitución y de la carta.

\section{LA FUTURA CONSTITUCIÓN EUROPEA Y LA CARTA DE LOS DERECHOS FUNDAMENTALES DE LA UNIÓN EUROPEA VISTOS DESDE IBEROAMÉRICA}

1. Una ponencia sobre la futura Constitución de Europa y la Carta de los Derechos Fundamentales de la Unión Europea escrita en Iberoamérica, por un iberoamericano, a mediados de 2003, presenta, además de la importancia y trascendencia del tema en sí mismo, un doble interés adicional.

En primer lugar, por la particularidad del asunto mirado desde Iberoamérica, en relación con la situación interna e internacional actual de la región comparada con la existente en Europa.

En segundo lugar por el momento, cuando la futura Constitución de Europa está en pleno proceso de elaboración, con diferencias, hasta con enfrentamientos teóricos y políticos, respecto de algunos de sus elementos, contenidos y enfoques, después de la fractura que significó la Guerra de Irak, de los intentos de reacomodamiento posteriores y en cuanto se ha reactualizado la falta de unanimidad en lo que se refiere a la unidad monetaria, basada en la aceptación del euro.

En cuanto al primer punto, es evidente que la situación actual de Iberoamérica es muy diferente de la existente en la Unión Europea. Los procesos de integración regional existentes, pese a su importancia económica y política, siguen siendo hoy sólo acuerdos entre Estados regidos por el derecho internacional.

No puede hablarse de la existencia de un verdadero derecho comunitario, aunque hay atisbos de su posible existencia futura si se sigue, como es presumible que así sea, en un camino que ya se vislumbra. Ni el sistema interamericano, ni ninguno de los procesos de integración, en su forma institucional existente en la actualidad, constituyen otra cosa que el resultado de tratados internacionales entre Estados.

En tal situación, el concepto mismo de Constitución, como instrumento jurídico para regir a uno o varios de esos sistemas internacionales 
interetáticos actualmente existentes, constituye algo muy difícilmente concebible hoy, temporalmente lejano en Iberoamérica.

La idea de Constitución en Iberoamérica continúa siendo, como lo fuera tradicionalmente en el derecho constitucional europeo, un concepto unido con la idea y con la forma política y jurídica llamada Estado, ${ }^{1}$ aunque por extensión la doctrina latinoamericana fue pionera en aplicar el calificativo de derecho constitucional al derecho de la organización de la comunidad internacional fundada en la Carta de las Naciones Unidas. ${ }^{2}$

Constitución, derecho constitucional y Estado han sido tradicionalmente conceptos que se implican recíprocamente. ${ }^{3}$ Pero esta idea ha comenzado a cambiar en Europa.

El paso del tiempo no ha modificado hasta hoy este pensamiento iberoamericano. En cambio, en Europa el proceso de integración, cada vez más acentuado y totalizante, caracterizado por un contenido político - además de la idea política, existente, en sus fundamentos, principios y objetivos-, llevó a concebir la posibilidad de una Constitución para ese conjunto comunitario europeo, que era - y que sobre todo debía ser-, algo más que una suma internacional de Estados soberanos. ${ }^{4}$ Nació así la perspectiva de un derecho constitucional europeo que fuera algo diferente de un derecho constitucional comparado de Europa, destilación de los principios resultantes de la tradición y de la realidad institucional y política actual del continente europeo.

La idea de la existencia de un derecho constitucional europeo, necesariamente unido con el concepto de democracia y con el respeto de los derechos humanos, ${ }^{5}$ junto con la realidad de una Europa integrada en lo

1 Ruiz Miguel, C., "Transformación del derecho constitucional europeo", Anuario de Derecho Constitucional y Parlamentario, Universidad de Murcia, núm. 14, 2002, p. 120; Barile, Paolo, La constituzione come norma giuridica, Firenze, 1951, p. 33.

2 Jiménez de Aréchaga, Eduardo, Derecho constitucional de las Naciones Unidas, Madrid, Escuela de Funcionarios Internacionales, 1958.

3 Barile, Paolo, op. cit., nota 1, p. 32.

4 García Gestoso, Noemí, "Algunas cuestiones sobre la soberanía en el proceso de integración europea", Revista de Derecho Político, Madrid, Universidad Nacional de Educación a Distancia, núm. 57, 2003.

5 Cruz Villalón, Pedro, La curiosidad del jurista persa y otros estudios sobre la Constitución, Madrid, Centro de Estudios Constitucionales, 1999, en especial: "Formación y evolución de los derechos fundamentales"; y Aragón, Manuel, "Derecho constitucional y democracia", El País, Madrid; Vega, Pedro de, "Constitución y democracia", La Constitución de la monarquía parlamentaria, Madrid, FCE, 1983; Ruipérez, Javier, La Constitución Europea y la teoría del poder constituyente, Madrid, 2000; Tajadura Tejada, Javier, "La crisis de la Constitución en el proceso de integración europea, cap. II. El principio democrático", Revista de Derecho Político, Madrid, núm. 
económico, parcialmente en lo político y en muy importantes aspectos jurídicos y sociales, ${ }^{6}$ está en el origen del pensamiento sustentador de la posibilidad de una Constitución Europea, concebida como una etapa posterior, como un perfeccionamiento y en cierto sentido una superación de la etapa en que la Unión Europea fue — y es aún - resultante sólo de tratados internacionales entre Estados. No puede olvidarse a este respecto que toda Constitución cumple una función de "unificación del sistema jurídico", 7 y que sin duda este efecto de una futura Constitución se ha de producir con respecto a la Unión Europea. No es posible, asimismo, dejar de recordar que el concepto de Constitución implica la idea de supremacía, la de cúspide de un ordenamiento jurídico. ${ }^{8}$

La diferencia existente, por tanto, entre Iberoamérica y Europa, en lo que se refiere a la aplicación de nuevas formas políticas, distintas del Estado tradicional, justifica plenamente un enfoque diverso de la cuestión de la Constitución Europea y de la Carta Europea de los Derechos Fundamentales, hecho desde la costa americana del Atlántico.

En lo que se refiere al segundo enfoque. Estamos hoy, cuando escribo estas líneas, a unos meses del VIII Congreso Iberoamericano de Derecho Constitucional de Sevilla (diciembre de 2003), inmediatamente después de la Cumbre de Salónica (Porto Carras) en un momento muy especial del proceso de elaboración de la futura Constitución Europea. A comienzos de 2002 no se pensaba en la fractura que los prolegómenos de la Guerra de Irak y esta Guerra en sí misma, habría de producir en la política de los países de la Unión Europea. Esta fractura y además, la imposibilidad en los días que corren de una unificación monetaria, en virtud, en especial, de la postergación de la aceptación por Gran Bretaña del

53, 2002, pp. 246-251. El carácter necesariamente democrático de la Unión Europea y de los Estados miembros se encuentra impuesto y reafirmado por los Tratados de Maastrich (1992), Ámsterdam (1997) y Niza (2000).

6 Tarea esencial del Consejo de Europa, organización internacional distinta de la Unión Europea, dedicada, en especial, a la elaboración de instrumentos en el campo jurídico, en particular en cuanto a los derechos humanos, dentro de cuyo marco nació la Convención Europea de Derechos Humanos de 1950, cuyo órgano de aplicación es hoy la Corte Europea de Derechos Humanos (Estrasburgo). Véase Levy, Paul M. G., "The Council of Europe", Europe, Dream -AdventureReality, Brussels, Elsevier, 1992.

7 Mortati, Constantino, La Constituzione in senso materiale, Milán, 1940, cap. III, 3b (L'unificazione del sistema giuridico), pp. 47-150.

8 Nogueira Alcalá, Humberto, "Consideraciones sobre la jurisdicción constitucional en América y Europa", Anuario Iberoamericano de Justicia Constitucional, Madrid, Centro de Estudios Políticos y Constitucionales, t. 4, 2000. 
euro, hacen que el momento actual sea particularmente complejo para la culminación exitosa del proceso que conducirá a la adopción de lo que habrá de ser la Constitución de Europa.

El futuro, por tanto, aún siendo optimista, está lleno de incertidumbres y dudas, que sólo el paso del tiempo permitirá aclarar.

2. Hay otra precisión preliminar que hay que hacer. La Carta de Derechos Fundamentales, sobre la que luego fijaremos especialmente nuestra atención, se suma a la Convención Europea para la Protección de los Derechos Humanos y de las Libertades Fundamentales del Consejo de Europa, así como a sus múltiples protocolos adicionales. Esta convención es un tratado internacional del que son partes los Estados miembros del Consejo de Europa, muchos de los cuales son, a su vez, o lo serán próximamente, miembros de la Unión Europea.

En el sistema interamericano existe una convención, la Convención Americana sobre Derechos Humanos (Pacto de San José), que tuvo como una de sus fuentes a la Convención Europea, que se funda en principios análogos y posee una estructura similar a ésta. ${ }^{9}$ La Convención Americana, de la que no son parte ni los Estados Unidos de América ni Canadá ni algunos Estados de lengua inglesa del Caribe, es en el continente americano un texto paralelo a lo que es en Europa la Convención para la Protección de los Derechos Humanos y de las Libertades Fundamentales de 1950 y sus Protocolos Adicionales.

Pero no hay en Iberoamérica ni se encara la existencia futura de algo análogo a la Carta de Derechos Fundamentales de la Unión Europea, por las mismas razones que ya hemos expresado, con respecto a la inexistencia en América de un proceso similar al europeo que pudiera conducir a la existencia de una Constitución Iberoamericana.

\section{LA FUTURA CONSTITUCIÓN EUROPEA}

1. La futura Constitución Europea está hoy en pleno proceso de elaboración, luego de la aprobación en Salónica (Grecia, Porto Carras) en junio-julio de 2003, del proyecto de la convención presidida por Valery

9 Gros Espiell, Héctor, "La Convention Europeénne et la Convention Americaine des Droits de l'Homme, Analyse Comparative", Recueil des Cours, La Haye, Academie de Droit International, t. 218, 1989. 
Giscard D'Estaing, proceso que deberá terminar presumiblemente con su adopción final en 2006.

Hay que comenzar, por tanto, por resumir el proceso que llevó a la idea de cristalizar en un texto escrito, en un instrumento que tuviera el carácter de una Constitución formal, con un contenido material y con una jerarquía propia y específica, que constituyera una etapa distinta y posterior a la que institucionalizó la Unión Europea, con base únicamente en tratados internacionales multilaterales, en lo relativo a los principios y a la organización institucional de esta unión. Aunque estos tratados han sido calificados como "la Carta constitucional de una Comunidad de Derecho" por el Tribunal de Justicia de la Comunidad Europea y por una cierta doctrina, ${ }^{10}$ no hay duda de que estos tratados son algo diferente de la Constitución cuya elaboración y aprobación se encara ahora.

Este resumen debe ser continuado con la somera descripción del proceso de elaboración de esa futura Constitución, de los apoyos que ha recibido y de las críticas que ha generado.

2. Pese a que esta futura Constitución, por lo menos a corto y mediano plazo, deberá necesariamente emanar de un tratado internacional, la idea de esa Constitución se construyó en parte, con base en una concepción diferente: la de que esta Constitución por su contenido, y por sus elementos simbólicos, pudiera ser entendida como tal, con toda la carga tradicional y política que el concepto de Constitución tiene en la historia europea y que, además, por el procedimiento o método ideado para la elaboración del proyecto, éste fuera, por lo menos en su fase inicial, algo distinto del clásicamente usado - las conferencias diplomáticas integradas exclusivamente por representantes gubernamentales de Estadospara la elaboración de los tratados multilaterales. ${ }^{11}$

10 Rodríguez Iglesias, Gil Carlos, ¿¿Una Constitución para Europa?”, El País, Madrid, 1o. de marzo de 2002; Pereira Menant, Antonio Carlos, "Introducción al estudio de la Constitución de la Unión Europea", Revista de Derecho Político, Madrid, Universidad Nacional de Educación a Distancia, núm. 53, 2002, pp. 209 y ss.; Fernández Esteban, Ma. L., "La noción de Constitución Europea en la jurisprudencia del Tribunal de Justicia de las Comunidades Europeas", Revista Española de Derecho Constitucional, Madrid, núm. 40, 1994; Conseil de l'Europe, Comission de Venise, Le Droit Constitutionnel et l'Integration Europeenne (CDL. Inf. (99)7), Estrasburgo, 21 avril 1999, Rapport de synthése de Armando Toledano Laredo, que cita (p. 11), el point 21 de l'Avis $\mathrm{N}^{\circ}$. 1/91 de 14 de diciembre 1991, en cuanto dice:"...le traité CEE, bien qui conclu sour la forme d'un accord international, n'en constitue pas moins la Charte Constitutionnelle d'une Communauté de Droit".

11 Gros Espiell, Héctor, Una Constitución para Europa, Montevideo, Patria, 15 de marzo de 2002; Díaz Preazo, L., "Reflexiones sobre la idea de Constitución Europea", Revista de Instituciones 
La convención, organismo atípico integrado por representantes del Parlamento Europeo, los parlamentos nacionales, los gobiernos y la comisión, con representantes de los países candidatos a la adhesión, sin derecho a voto, llegó el 13 de junio de 2002 en Bruselas, luego de 15 meses de trabajo, a un acuerdo sobre el proyecto de Constitución para la Europa ampliada.

Según Giscard D’Estaing, la convención al preparar el proyecto de Constitución, combinó “idealismo e innovación para avanzar con realismo político para construir".

Este proyecto fue presentado a la Cumbre de Salónica (Porto Carras) en la reunión celebrada entre el 19 y 21 de junio del 2003 y aprobado en principio, sin perjuicio de retoques futuros y de puntos en los que no se logró un acuerdo final.

Para la percepción de la "ciudadanía europea", para el europeo que piensa en función de la historia en virtud de la cual se formó y es, la idea de una Constitución para Europa es algo muy distinto de lo que puede ser un tratado o un conjunto de tratados internacionales, unidos necesariamente a la idea de un derecho internacional aplicable a un conjunto de Estados, aunque ellos hayan llegado a constituir una comunidad de derecho regulada por un derecho comunitario.

3. Esta futura Constitución nacerá "de la voluntad de los ciudadanos y de los Estados de Europa de construir un futuro común...” (parte I, título I, artículo I-1: Creación de la unión, del proyecto aprobado en Salónica en junio de 2003).

Es decir, que el poder constituyente de la Unión Europea resulta no sólo de los Estados, sino de la conjunción de la voluntad de los Estados con la de los ciudadanos de la unión. ${ }^{12}$

Es un concepto novedoso y revolucionario, que innova de una manera esencial en la idea y en la forma de cómo constituir una nueva entidad política integrada por Estados.

Como lo ha dicho Robert Badinter:

Europeas, Madrid, 1993-2; García de Enterría, E., "El Proyecto de Constitución Europea”, Revista Española de Derecho Constitucional, Madrid, núm. 45, 1995.

12 La Pérgola, Antonio, "La unión a través de la ciudadanía europea. Una propuesta de la Comisión de Venecia”, en Gros Espiell, Héctor, Amicorum Liber, Bruxelles, Bruylant, 1997, vol. I, pp. 610-639. 
D’abord, les délégations de souveraineté consenties par les Etats-membres au long des traités successifs.

A cette souveraineté déléguée par les États s'en ajoute une autre, moins évidente mais plus directe: celle des citoyens de l'Union.

Se conjuguent ainsi, au sein de l'Union, deux sources de légitimité: celle des Etats-membres et celle du peuple de l'Union composé de l'ensemble des citoyens de l'Union, sans distinction de nationalité. ${ }^{13}$

4. El proceso para la redacción de la futura Constitución Europea, precedido de una concientización ideológica — fundada naturalmente en una idea de Europa ${ }^{14}$ y de sus principios tradicionales históricos y políticos y de la evolución de una opinión pública que había conocido ya iniciativas anteriores, como los proyectos Spinetta de 1984, Luster de 1989 y Hermann de 1994 presentados en el Parlamento Europeo, así como otras iniciativas y propuestas - ${ }^{15}$ comenzó realmente con la Declaración de Laecken del 15 de diciembre de 2001 sobre el futuro de la Unión Europea, que planteó concretamente la cuestión de si para que Europa llegase a ser más democrática, más transparente y más eficaz", no sería necesaria "la adopción de un texto constitucional".

Esta futura Constitución Europea fue concebida como un paso adelante en la existencia actual de un derecho comunitario, que a su vez, ya

13 Badinter, Robert, Une Constitution Européenne, París, Fayard, 2002, pp. 25 y 26.

14 Durosselle, Jean-Baptiste, "Qu'est-ce que l'Europe", en Durosselle, Jean Baptiste, L'Europe, Histoire de ses Peuples, Perrin, 1990, pp. 11-21; Brugmans, Hendrik, Europe: One Civilisation, one Destiny, once Vocation, in Europe, Dream-Adventure-Reality, cit, pp. 11-38. Esta "idea" de Europa es evidentemente algo más que un concepto geográfico. ¿Cómo no recordar a este respecto las palabras de Paul Valery?: 'L'Europe deviendra - t-elle ce qu'elle est en réalité, c'est-á dire: un petit cap du continent asiatique? Ou bien l'Europe restera - t-elle ce qu'elle paraît, c'est-á-dire: la partie précieuse de l'univers terrestre, la perle de la sphére, le cervau d'un vaste corps?". "Cette Europe triomphante qui est née de l'échange de toutes choses spirituelles et matérielles, de la coopération volontaire et involontaire des races, de la concurrence des religions, des systèmes, de intérèts, sur un teritoire très limité, m'apparait aussi animée qu'un marché où toutes choses bonnes et précieuses sont aportes, comparées, discutes, et changent de mains". "Je dirais presque, ma pensée abusant de mon langage, qu'une Europe est une espèce de système formé d'une certaine diversité humaine et d'une localité particulièrement favorable; faconnée en fin par une histoire singuliérement mouvementée et vivante. Le produit de cette conjoncture de circonstances est un Européen". Valery, Paul, Oeuvres, t. I : La Crise de l'Esprit, 2a. lêttre, París, Bibliotheque de la Pléiade, 1968, pp. 995, 1005, 1007.

15 Una enumeración de estos antecedentes puede encontrarse en Molina del Pozo, Carlos Francisco (dir.), Comentarios al Proyecto de Constitución Europea, Granada, Editorial Comanes, 1996, pp. 2 y ss. 
había superado el enfoque anterior de concebir la Unión Europea como un sistema basado en la aplicación exclusiva del derecho internacional. ${ }^{16}$

5. No hemos de seguir paso a paso el proceso de elaboración del proyecto de Constitución, preparado por la convención presidida por Valery Giscard D'Estaing, ${ }^{17}$ que ha sido comentado, a partir del conocimiento del primer ante proyecto o borrador en octubre de 2002, por una importante doctrina ${ }^{18}$ y que dio lugar a proyectos o contribuciones paralelos, entre las cuales destaca el libro de Robert Badinter. ${ }^{19}$

6. Cuando se escriben estas líneas, en julio de 2003, el proceso se encuentra en la siguiente situación. En los últimos meses de 2002, Giscard D’Estaing presentó el "esqueleto" o anteproyecto de Constitución preparado por la convención que calificó de "prudente, razonable, pero no carente de ambición”. Lógicamente la polémica siguió a esta primera presentación del anteproyecto, no sólo entre los partidarios y los contrarios a la idea de una Constitución para la Unión Europea, sino entre los que, siendo favorables, discrepaban con determinadas soluciones, fórmulas o enfoques.

A través de sucesivas etapas, luego de la aprobación del proyecto por la convención, en junio de 2003, en Bruselas, se ha llegado, cuando escribimos estas líneas, en junio 19-22 de 2003, a la reunión cumbre de Salónica (Porto Carras), en que el proyecto de Constitución ha sido oficialmente presentado a esta instancia decisiva, última que se ha de celebrar bajo la presidencia griega, a la que le seguirá la presidencia italiana. Y la cumbre lo aprobó.

Luego del debate en Salónica, que constituyó un triunfo para el proyecto elaborado por la convención, presidida por Giscard D’Estaing, la

16 Gutiérrez Espada, Cesáreo, "De nuevo sobre las relaciones entre la Constitución y el derecho comunitario", Anuario de Derecho Constitucional y Parlamentario, Madrid, núm. 10, 1998.

17 Valery Giscard D'Estaing, como presidente de la convención y principal redactor del proyecto elaborado y presentado por ésta, ha escrito innumerables artículos y concedido muy numerosas entrevistas de prensa. He tenido en cuenta las publicaciones hechas en Le Figaro, Le Monde, Liberation, El Pais y $A B C$.

18 La amplísima bibliografía sobre el tema que es en su mayoría anterior a la redacción del proyecto examinado en Salónica, es imposible citarla aquí en su integridad. Parte importante de ella se encuentra referida en las notas de esta ponencia. Naturalmente es una bibliografía especial y particularmente europea a la que la doctrina latinoamericana no ha agregado hasta hoy, con alguna excepción, aportes de significativa importancia. La consideración del proyecto de Constitución adoptado en Salónica provocará, sin duda, el surgimiento de una nueva y abundante bibliografía sobre este proyecto.

19 Badinter, Robert, op. cit., nota 13. 
misma convención procederá a retocar el proyecto, recogiendo los resultados de la reunión de Salónica, que será presentado a los gobiernos reunidos en una conferencia intergubernamental.

Es imposible, realísticamente, predecir hoy como terminará el proceso de adopción de la Constitución Europea, luego de la prevista conferencia intergubernamental, que será precedida seguramente de intensas y difíciles negociaciones políticas.

Hay temas concretos aún sin resolver, como por ejemplo: ¿cómo se tomarán las decisiones en cada país miembro de la unión? Y además, en cuanto a la formalización del proceso, ¿cómo tomará su decisión cada Estado miembro?, ¿habrá referéndum nacionales? El camino a recorrer no es, por tanto, nada fácil. Pero está iniciado el proceso, ha progresado mucho, no puede ser abandonado y es imposible retornar a lo que existía antes de que la idea de una Constitución Europea naciera y germinara. La crítica de alguna doctrina que, en 2002, sostenía que la idea de una Constitución Europea era todavía "prematura", parece que hoy ya no se mantiene y que pese a las dificultades y obstáculos que habrá de salvar, la idea en sí misma, es decir de la pertinencia de una Constitución Europea, ha sido mayoritariamente aceptada.

En noviembre de 2003, luego del fracaso de la conferencia intergubernamental, en su intento de lograr un consenso - y cuando continúan las discrepancias en especial respecto del sistema de votación en los órganos previstos en la futura Constitución - resulta evidente que el proceso de adopción del proyecto habrá de tardar, sin duda más allá del fin de 2003 y que sólo será posible esperar un eventual acuerdo en el curso de 2004.

7. No hemos de entrar a la cita de cada una de las etapas cumplida hasta hoy ni a los distintos aspectos del debate que ha generado el tema y el proyecto de Constitución Europea de su proceso redaccional. Sólo deseamos señalar que el proyecto presentado en Salónica, además de incluir como contenido lo referente a la relación de la futura Constitución con la Carta de Derechos Fundamentales de la Unión Europea, ha tenido como uno de sus puntos más importantes y controversiales el tema de la inexistencia de referencias a Dios y al aporte religioso a la idea de Euro- 
pa, asunto sobre el que ha hecho especial hincapié la Iglesia Católica, a través de múltiples pronunciamientos, incluso del papa Juan Pablo II. ${ }^{20}$

8. El contenido del proyecto de Constitución es análogo, en principio, y en general, al de las Constituciones europeas que forman el actual derecho constitucional comparado de Europa. Pero su materia, mucho más compleja, está condicionada por el hecho de que se trata de una Constitución tan atípica como la que resulta de un texto que ha de regir para el conjunto de Estados que forman la Unión Europea, al mismo tiempo que para una población europea que debe ser considerada en su carácter de tal. Deberá, en consecuencia, encarar cuestiones que generalmente escapan a las constituciones estatales.

Contendrá sin duda un preámbulo, los principios fundamentales constitutivos, lo relativo a los derechos fundamentales, ya que la futura Constitución se integrará con la Carta Europea de Derechos Fundamentales, ${ }^{21}$ a la ciudadanía europea, ${ }^{22}$ a la estructura orgánica, al régimen de votación y al tipo de mayoría que se exigirá para las decisiones de sus órganos colectivos. La cuestión del tipo de votación y de las mayorías es un tema tremendamente polémico, en el que se manifestaron en Salónica discrepancias muy hondas y subsisten hoy. A todo esto se agregará lo relativo a la defensa y a la política exterior.

Los temas son, en consecuencia, de una complejidad abrumadora y presentan dificultades graves. El trabajo a realizar es aún muy grande y los plazos para encontrar las soluciones no pueden ser breves.

20 Mensaje de Juan Pablo II a la Conferencia de la Universidad Católica de Roma sobre la Constitución de la Unión Europea, (22 de junio de 2002); Declaración de los Presidentes de las Conferencias Episcopales Europeas (22 de octubre de 2002, Lovaina); Declaración de los Cristianos por Europa, 22 de febrero de 2003, Barcelona. Frente a esta actitud, 252 parlamentarios de los 15 miembros de la Unión Europea han firmado un "Llamamiento para el respeto de los principios de libertad religiosa y de laicidad del Estado en la futura Constitución europea". Un punto de vista sumamente interesante es el de Fernando Savater, quien reconociendo las raíces cristianas de Europa, apoya y comparte el criterio seguido por el proyecto de la convención presidida por Giscard D’Estaing. Savater. Fernando, "Raíces cristianas y la Constitución”, El País, Montevideo, 10 de agosto de 2003.

21 Díaz Picazo, L. M., “Una Constitución sin declaración de derechos? (reflexiones constitucionales sobre los derechos fundamentales en la Comunidad Europea)", Revista Española de Derecho Constitucional, Madrid, núm. 32, 1991.

22 Proyecto de Constitución Europea, parte I, título II (De los derechos fundamentales y ciudadanía de la unión); Carta de los Derechos Fundamentales de la Unión Europea, capítulo V (Ciudadanos), artículos 39, 40 y 42, que se refieren a "todos los ciudadanos de la Unión". Campos, P. Biglimio, "Ciudadanía europea y legitimidad democrática", Revista de Estudios Europeos, núm. 9, 1995; Blázquez Peinado, Ma. D., La ciudadanía de la unión, Valencia, 1998; La Pérgola, Antonio, op. cit., nota 12. 
Pero el camino se ha iniciado y se ha previsto que termine en el año en un plazo predeterminado.

Este es uno de los casos en que, como ya dijimos, iniciado el camino, el mismo no puede ser abandonado, ni es posible regresar a la situación anterior.

9. El tema de los derechos humanos no puede, ni podrá estar ajeno a la Constitución en proceso de elaboración. No sólo hay claras y expresas referencias a ese asunto en el proyectado preámbulo, sino también en lo referente a los "valores" de la Unión Europea.

Estos "valores" de la Unión Europea entre los que cabe declarar aquí, la dignidad humana, la libertad, la democracia, la igualdad y los derechos humanos, constituyen, asimismo, en cuanto a los derechos fundamentales garantizados por la Convención Europea para la Protección de los Derechos Humanos y de las Libertades Fundamentales, "principios generales" integrantes del "derecho de la unión". En efecto el artículo I-7.3 dispone: "I-7:3. Los derechos fundamentales que garantiza el Convenio Europeo para la Protección de los Derechos Humanos y de las Libertades Fundamentales y los que son fruto de las tradiciones constitucionales comunes a los Estados miembros forman parte del Derecho de la Unión como principios generales".

Pero además, el asunto está presente en la cuestión - que involucra varios aspectos y decisiones a tomar-, de la relación entre la futura Constitución y la Carta Europea de los Derechos Fundamentales.

El preámbulo proyectado dice respecto de la democracia, la libertad y los derechos humanos en la futura Constitución:

Nuestra Constitución se llama democracia... porque el poder no está en manos de unos pocos sino de la mayoría. Tucídides II, 37.

Conscientes de que Europa es un continente portador de civilización, de que sus habitantes, llegados en sucesivas oleadas desde los albores de la humanidad, han venido desarrollando los valores que sustentan el humanismo: la igualdad de las personas, la libertad y el respeto a la razón.

Con la inspiración de las herencias culturales, religiosas y humanitarias de Europa, cuyos valores siguen presentes en su patrimonio y han hecho arraigar en la vida de la sociedad su visión del valor primordial de la persona y de sus derechos inviolables e inalienables, así como el respeto del derecho.

En el convencimiento de que la Europa ahora reunida proseguirá por esta senda de civilización, progreso y prosperidad en bien de todos sus ha- 
bitantes, sin olvidar a los más débiles y desfavorecidos; de que esa Europa quiere seguir siendo un continente abierto a la cultura, al saber y al progreso social; de que desea ahondar en el carácter democrático y transparente de su vida pública y obrar en pro de la paz, la justicia y la solidaridad en el mundo.

Y en cuanto a los valores, el artículo I-2 expresa: "La Unión se fundamenta en los valores de respeto a la dignidad humana, libertad, democracia, igualdad, Estado de derecho y respeto a los derechos humanos. Estos valores son comunes a los Estados miembros en una sociedad caracterizada por el pluralismo, la tolerancia, la justicia, la solidaridad y la no discriminación".

En lo que se refiere a la relación entre la futura Constitución y la Carta Europea de los Derechos Fundamentales, la cuestión está regulada en el título II del proyecto de Constitución (De los derechos fundamentales y la ciudadanía de la unión).

Así es que el artículo I-7 establece:

1. La Unión reconoce los derechos, libertades y principios enunciados en la Carta de los Derechos fundamentales que constituye la segunda parte de la presente Constitución.

2. La Unión procurará adherirse al Convenio Europeo para la Protección de los Derechos Humanos y de las Libertades Fundamentales. La adhesión a dicho Convenio no afectará a las competencias de la Unión que se definen en la presente Constitución.

3. Los derechos fundamentales que garantiza el Convenio Europeo para la Protección de los Derechos Humanos y de las Libertades Fundamentales y los que son fruto de las tradiciones constitucionales comunes a los Estados miembros forman parte del Derecho de la Unión como principios generales.

10. ¿Es necesaria hoy una Constitución para la Unión Europea?23 Aunque esta cuestión en este momento es objeto de un renovado debate, la posición mayoritaria - aunque con un abanico de diferentes posiciones y criterios - parece ser ampliamente favorable a la idea de la necesidad de una futura Constitución. El tema sigue abierto. 
Por mi parte tengo una posición favorable a la idea. Creo que la necesidad de esta Constitución se acentúa frente a la realidad de hoy y que esta necesidad es ahora mayor que la que ya existía en 2000 .

Una Constitución es un imperativo ineludible para dar un paso cierto y determinante en el proceso de unificación de Europa, para pasar a ser una comunidad fundada en el derecho comunitario, que en última verdad está determinada por el derecho internacional, a ser algo más estricto y profundo, a ser una comunidad regida por una Constitución que será expresión de la voluntad de los Estados parte y, además, de la ciudadanía europea, de una ciudadanía común, expresión final y fuente última de la soberanía en Europa.

$\mathrm{Y}$ este proceso de constitucionalización pienso que tendrá efectos fructíferos, no sólo para la Unión Europea, sino para la comunidad internacional, en su conjunto, ya que puede llegar a ser un elemento para impulsar el deseable reequilibrio de poder, necesario para que esta comunidad universal, que todos integramos, sea realmente equilibrada, pluralista, y multipolar.

Pero no puedo dejar de manifestar mis dudas y temores. El peso, la importancia capital de los Estados nacionales que integran la unión, las diferencias políticas y los distintos criterios económicos que subsisten, son elementos que no pueden dejarse de considerar al reflexionar sobre el tema.

11. Subjetivamente, como fundamento personalísimo de mi actitud positiva y favorable, deseo citar las hermosas palabras de Robert Badinter que, en última instancia, provocan y generan mi actitud. Dicen así: "J'aime les constitutions. Toute constitution est à la fois un instrument politique, une architecture juridique, un moment historique et une oeuvre littéraire". ${ }^{24}$

A estas bellas expresiones, yo sólo quiero agregar lo que hace muchos años, en 1985, escribí cuando el Uruguay retornó a la democracia: "La Constitución retomó, de tal modo su significado más alto: el de ser no sólo un conjunto de normas situadas en la cúspide normativa del orden jurídico estatal, sino el de simbolizar las aspiraciones democráticas del pueblo y constituir la bandera de la lucha por el progreso, el 
desarrollo y la convivencia pacífica de todos en un orden de libertad y justicia". 25

La Constitución proyectada será, así, un símbolo de Europa.

\section{LA CARTA DE LOS DERECHOS FUNDAMENTALES DE LA UNIÓN EUROPEA}

1. Corresponde ahora entrar al tema de la Carta de los Derechos Fundamentales de la Unión Europea. ${ }^{26}$ Este texto, ya en vigencia, es un instrumento internacional de la Unión Europea. Unión Europea y Consejo de Europa son organizaciones internacionales distintas, con diferente membresía, aunque entre ambas hay evidentemente una similitud de principios, una incidencia común, una comunión de ambas en cuanto a la idea de Europa y a todo lo que resulta de su tradición y de su historia.

No puede dejarse de señalar que en la Unión Europea, desde hace ya muchos años, existe, basado en la jurisprudencia del Tribunal de Justicia de las Comunidades Europeas, con sede en Luxemburgo, un cierto control del respeto de los derechos humanos - que forman parte de los principios generales cuyo respeto este tribunal debe asegurar- en los países miembros de la unión en su accionar dentro del marco de esta unión.

La Carta Europea de Derechos Fundamentales de la Unión Europea y la Convención Europea de Derechos Humanos del Consejo de Europa son, además, diferentes por su naturaleza jurídica.

La carta es todavía hoy un texto no convencional. No nació ni se sustenta actualmente en un tratado multilateral entre los Estados partes de la

25 Gros Espiell, Héctor, "El Uruguay en la actual evolución constitucional democrática en Iberoamérica", en Estudios constitucionales, Montevideo, Ingranusi, 1998, p. 169.

26 Gros Espiell, Héctor, "La Carta de Derechos Fundamentales de la Unión Europea", Revista de Derecho Público, núm. 19, Montevideo, Fundación de Cultura Universitaria, 2001; Herrero de la Fuente, Alberto, La Carta de Derechos Fundamentales de la Unión Europea: una perspectiva pluridisciplinaria, Zamora, Cuadernos del Instituto Rei Afonso Henriques de Cooperación Transfronteriza, 2003; Weber, Albertche, "La Carta Europea de los Derechos Fundamentales desde una perspectiva comparada", en varios autores, Derechos Fundamentales y Estado, Memoria del VII Congreso Iberoamericano de Derecho Constitucional, México, 2002, p. 729; Decaux, Emmanuel, "Héritage Religieux et Droits de l'Homme (à propos de la Charte des Droits Fondamentaux de l'Union Europèene)", en varios autores, Mèlanges Offerts à Silvio Marcus Helmon, Bruxelles, Bruylant, 2003, p. 41; Wathelet Melchior y Raepenbush, Sean van, "La Protection des Droits Fondamentaux au Sein de l'Union Europèene aprés la Traitè de Nice", en varios autores, Mèlanges Offerts..., cit, en esta misma nota, p. 345; Braibant, G., "Vers une Charte des Droits Fondamentaux de l'Union" (table ronde du 18-V-2000 organisée par Cohen-Jonathan, decaux et dutherie de la Rochère), La Documentation Francaise, núm. especial 264, aout 2000. 
Unión Europea. Esa es su situación al día de hoy. La cuestión cambiará cuando se resuelva el tema de su relación con la futura Constitución Europea.

En cambio, la Convención Europea para la Protección de los Derechos Humanos y de las Libertades Fundamentales es un tratado, o mejor dicho un sistema fundado en un tratado original y en sus múltiples protocolos adicionales. Es un sistema de naturaleza convencional, con la consiguiente fuerza jurídica, que posee un régimen orgánico y funcional de vigilancia en su aplicación, para asegurar el control y garantía internacional, de naturaleza jurisdiccional, de los derechos y libertades.

Tener en cuenta esta distinta situación actual de los dos instrumentos es fundamental, para analizar la naturaleza jurídica, el contenido y el sistema de control de la aplicación de la Carta Europea y para poder encarar su posible futuro.

Sin embargo, hay que considerar que el Proyecto de Constitución de la Unión Europea encara la adhesión de la Unión al Convenio Europeo para la Protección de los Derechos Humanos y de las Libertades Fundamentales (artículo I-7, 2 del título II) y que los "derechos fundamentales que garantiza este Convenio [y] los que son fruto de las tradiciones constitucionales comunes a los Estados miembros [,] forman parte del Derecho de la Unión como principios generales" (artículo I-7, 3 del título II).

2. La carta fue elaborada por una convención encargada de esa tarea por el Consejo Europeo, convención integrada por representantes de los gobiernos, de los parlamentos nacionales y de parlamentarios europeos. Fue dirigida por el presidente Herzog. El proyecto de la convención fue adoptada por la Cumbre de Niza en diciembre de 2002.

3. La carta ha recogido, naturalmente, elogios y críticas. En cuanto a los primeros, coinciden, en general, con los criterios que afirmo a continuación. Pero no han faltado las críticas, que pensamos que son exageradas e injustas, resumidas en un reciente estudio de particular interés, que califica a la carta de "conjunto desordenado de derechos, principios generales y normas programáticas de comportamiento". ${ }^{27}$

27 Zanghi, Claudio, "Premières Observations sur la Charte de Droits Fondamentaux de l'Union Europèene", en varios autores, Mèlanges Offerts..., cit., nota anterior, p. 377. 
4. En un análisis preliminar de la Carta Europea, que realicé en enero de 2001, califiqué a este instrumento como "un texto vivo e innovador". 28

\section{Dije entonces:}

En materia de derechos humanos, y de su protección interna e internacional, nada es —ni debe ser- estático. El reconocimiento expreso de nuevos derechos y su necesaria protección, mediante adecuadas garantías, es la consecuencia del carácter abierto de esta temática y de su necesaria evolución —en el respeto de principios inalterables, emanados de la dignidad humana y de la moral—, acompañando los cambios sociales y los avances científicos y tecnológicos.

La Carta Europea de Derechos Fundamentales es un ejemplo de apertura y de innovación, de comprensión de la incidencia necesaria de los cambios sociales y culturales en la cuestión de los derechos humanos y de la impuesta recepción de las consecuencias de los progresos de la ciencia y de la tecnología en esta cuestión, pero al mismo tiempo de respeto de la tradición y de los grandes principios fundamentales en materia de garantía, defensa y protección de los derechos humanos.

En tal sentido, la Carta Europea de Derechos Fundamentales, además del valor que tiene hoy y del que tendrá en el futuro en la Unión Europea, cuando forme parte de su Constitución, constituye un ejemplo de particular interés para los países iberoamericanos.

5. Hay además que destacar que esta modernidad, apertura e innovación, han permitido que la carta incluya cuestiones que no se encuentran expresamente encaradas en la Convención Europea para la Protección de los Derechos Humanos y las Libertades Fundamentales del Consejo de Europa. Es el caso, entre otros muchos de: la protección del medio ambiente (artículo 37), la protección de los consumidores (artículo 38) y el derecho a la integridad física y psíquica en el marco de la medicina y la biología, en especial en lo que se refiere al consentimiento libre e informado, la prohibición de la eugenesia y de las prácticas que tienen por finalidad la selección de las personas, la prohibición de que el cuerpo humano o partes del mismo se conviertan en objeto de lucro y la prohibición de la clonación reproductora de seres humanos (artículo 3).

28 Gros Espiell, Héctor, "Un texto vivo e innovador", El Observador, Montevideo, 10 de enero de 2001 . 
Todo esto, además de una actualización de la formulación de la caracterización de los derechos protegidos, en función de las realidades de hoy, utilizando asimismo una visión prospectiva.

6. La Carta Europea se titula Carta de los Derechos Fundamentales. Opta así por una terminología que no utiliza la expresión derechos humanos. Es una fórmula, la de derechos fundamentales, que se encuentra en muchos de los textos constitucionales de los sistemas europeos, en algunos de los instrumentos internacionales regionales de Europa, y que se emplea corrientemente por la doctrina europea. Pero no es la expresión usada generalmente en el ámbito de las Naciones Unidas, no se utiliza en el Sistema Regional Americano de Protección de los Derechos Humanos, y que no sigue en general la doctrina latinoamericana del derecho internacional de los derechos humanos.

Sin entrar ahora al debate doctrinario respecto del sentido, naturaleza $\mathrm{y}$ alcance de las expresiones derechos humanos y derechos fundamentales, no puedo ocultar mi preferencia por la denominación derechos humanos. Si al decir derechos fundamentales quiere señalarse el carácter fundamental o esencial de todos los derechos humanos, nada encontraríamos de negativo o contraproducente en su empleo. En cambio, si al referirse a los derechos fundamentales se está insinuando que hay otros derechos humanos que no son fundamentales, y que por tanto están al margen, o discriminados, respecto de su protección internacional, e incluso de su protección constitucional interna, no me es posible disimular mi preocupación. A esto agrego que, eventualmente, el uso de la expresión derechos fundamentales, y no de la fórmula derechos humanos, podría llevar a exclusiones del reconocimiento de tales derechos, que han de ser siempre inherentes o innatos, a ciertas categorías de personas humanas, como por ejemplo los extranjeros y los inmigrantes ilegales, etcétera.

Naturalmente esta conclusión no desconoce la necesidad de distinguir - lo que hace el derecho internacional general-, entre los derechos en general, en particular, los "derechos civiles", los "económicos, los sociales y culturales", y los "derechos políticos", cuya titularidad puede ser atribuida sólo a los ciudadanos, así como el caso de los derechos que resultan de la nacionalidad.

Quiero creer, y tengo la esperanza de que esa fórmula de "derechos fundamentales", no sea contradictoria ni restrictiva de la que yo acepto y empleo, es decir "derechos humanos". 
7. Pasamos ahora a resumir, brevísimamente, el contenido de la carta. Se inicia con un extenso y evocador preámbulo. Sólo nos referiremos a dos extremos.

Primero. La afirmación del carácter abierto y evolutivo de la enumeración y garantía de los derechos humanos, "dotándolos de mayor presencia en una carta que refuerza la protección de los derechos fundamentales a tenor del progreso social y de los desarrollos científicos y tecnológicos".

Segundo. El reconocimiento expreso de que "el disfrute de los derechos origina responsabilidades y deberes tanto respecto de los demás como frente a la comunidad humana y las generaciones futuras".

Sin perjuicio de estas dos precisiones, es necesario señalar que el preámbulo "reafirma", respetando el principio de subsidiariedad, los derechos reconocidos por "las tradiciones constitucionales de los Estados miembros y las obligaciones internacionales de los Estados miembros.

La lectura completa del preámbulo de la carta es, sin embargo, necesaria para comprender cabalmente su sentido y su objeto.

Dice así:

Los pueblos de Europa, al crear entre si una Unión cada vez más estrecha, han decidido compartir un porvenir pacífico basado en valores comunes.

Consciente de su patrimonio espiritual y moral, la Unión está fundada sobre los valores indivisibles y universales de la dignidad humana, la libertad, la igualdad y la solidaridad, y se basa en los principios de la democracia y del Estado de derecho. Al instituir la ciudadanía de la Unión y crear un espacio de libertad, seguridad y justicia, sitúa a la persona en el centro de su actuación.

La Unión contribuye a la preservación y al fomento de estos valores comunes dentro del respeto de la diversidad de culturas y tradiciones de los pueblos de Europa, así como de la identidad nacional de los Estados miembros de la organización de sus poderes públicos en el plano nacional, regional y local; trata de fomentar un desarrollo equilibrado y sostenible y garantizada la libre circulación de personas, bienes, servicios y capitales, así como la libertad de este establecimiento.

Para ello es necesario, dotándolos de mayor presencia en una Carta, reforzar la protección de los derechos fundamentales a tenor de la evolución de la sociedad, del progreso social y de los avances científicos y tecnológicos.

La presenta Carta reafirma, respetando las competencias y misiones de la comunidad y de la Unión, así como el principio de subsidiariedad, los 
Derechos reconocidos especialmente por las tradiciones constitucionales y las obligaciones internacionales comunes de los Estados miembros, el tratado de la Unión Europea y los Tratados Comunitarios, el Convenio Europeo para la Protección de los Derechos Humanos y de las Libertades Fundamentales, las Cartas sociales adoptadas por la Comunidad y por el Consejo de Europa, así como por la Jurisprudencia del Tribunal de Justicia de las comunidades europeas y del Tribunal Europeo de Derechos Humanos.

El disfrute de tales derechos origina responsabilidades y deberes tanto respecto de los demás como de la Comunidad Humana y de las futuras generaciones.

En consecuencia, la Unión reconoce los derechos, libertades y principios enunciados a continuación.

8. La carta enuncia los “derechos fundamentales" distribuyéndolos en cinco capítulos (dignidad, libertades, igualdad, solidaridad, ciudadanía, justicia y disposiciones generales).

Es una clasificación novedosa que no sigue los modelos o ejemplos más conocidos ni los existentes en el derecho internacional - tanto los instrumentos de carácter universal como los de tipo regional- ni los del derecho constitucional estatal. No se afilia tampoco a las más divulgadas clasificaciones emanadas de la doctrina.

Adopta así, una propia clasificación capaz de provocar positivas reflexiones y algunas críticas. Yo, por mi parte - que nunca estuve convencido por la teoría de las generaciones de los derechos humanos y que prefiero llamarlos "nuevos derechos humanos", nacidos en el proceso nunca cerrado de normativización de derechos aparecidos, proclamados y protegidos como consecuencia de las nuevas necesidades humanas, individuales y colectivas, y que en cierta forma podrían considerarse implícitos, simplemente no enunciados_-, me felicito de este enfoque de la Carta Europea.

La carta es un instrumento distinto en su forma, pero novedoso y moderno, de proclamar derechos fundamentales. Es, en cuanto tal, que debe ser bienvenida. 
9. El capítulo I, de la carta, titulado "La Dignidad" se integra con cinco artículos: ${ }^{29} \mathrm{El}$ primero relativo a la inviolabilidad, el respeto y la protección de la dignidad humana. El segundo sobre el derecho a la vida. Su párrafo 2 establece que nadie puede ser condenado a la pena de muerte ni ejecutado. El tercero, relativo a la integridad de la persona, es especialmente actual y destacable. Después de afirmar que toda persona tiene derecho a su integridad física y mental, establece que "en el marco de la medicina y de la biología, deben en especial ser respetados: el consentimiento libre y esclarecido de la persona concernida, según las modalidades definidas por la ley; la interdicción de las prácticas eugenésicas y en especial aquellas que tienen por fin la selección de las personas, la prohibición de hacer del cuerpo humano o de sus partes, en tanto que tales, una fuente de beneficios económicos y la interdicción de la clonación humana reproductiva.

El artículo cuarto prohíbe la tortura y el quinto la esclavitud y el trabajo forzado.

El capítulo II se titula “ Libertades”. Declara el derecho a la libertad y a la seguridad (artículo 6), el respeto a la vida privada y familiar (artículo 7) y a la protección de los datos de carácter personal (artículo 8). Este artículo - sumamente interesante y necesario en el mundo en que vivimos - , da a "toda persona el derecho a acceder a los datos recopilados que le conciernen y de obtener su rectificación; todo ello bajo el control de una autoridad independiente".

El artículo 9 reconoce el derecho a contraer matrimonio y a formar una familia.

El 10 se refiere a la libertad de pensamiento, de conciencia y de religión y se refiere a la objeción de conciencia, que "se reconoce según las leyes nacionales que regulen su ejercicio".

El artículo 11 trata de la libertad de expresión y de información. El artículo 12 de la libertad de reunión y de asociación. El 13 establece que la libertad artística, de investigación, científica y la libertad de cátedra deben ser respetada. El artículo 14 es el relativo al derecho a la educación, a la gratuidad de la enseñanza, que debe ser obligatoria, a la libertad de enseñanza "en el respeto de los principios democráticos y al dere-

29 Gros Espiell, Héctor, "La dignidad humana en los instrumentos internacionales de derechos humanos", en varios autores, Dignidad humana, Cátedra Montevideo, UNESCO de Derechos Humanos, 2002. 
cho a los padres a asegurar la educación y la enseñanza de los hijos, conforme a sus convicciones religiosas, filosóficas y pedagógicas". E1 15 se refiere a la libertad profesional y al derecho al trabajo. Incluye el derecho de los trabajadores de terceros Estados a condiciones de trabajo iguales a los que benefician a los ciudadanos o ciudadanas de la unión. El siguiente artículo reconoce la libertad de empresa. El 17 garantiza el derecho de propiedad. Se prevé su privación "por causa de utilidad pública en los casos y condiciones previstas por una ley y mediante, en tiempo útil, el pago de una justa indemnización". Se protege la propiedad intelectual. El artículo 18 garantiza el "derecho de asilo en el respeto de las reglas de la Convención de Ginebra del 28 de julio de 1951 y del Protocolo del 31 de enero de 1967". El artículo 19 prohíbe las expulsiones colectivas y proscribe las expulsiones o extradiciones hacia un Estado donde exista un serio riesgo de aplicación de pena de muerte, de tortura o de otras penas o tratamientos inhumanos o degradantes. El capítulo III trata de la "igualdad". El artículo 20 proclama la igualdad ante la ley. El 21 prohíbe toda discriminación. El 22 asegura el respeto de la diversidad cultural, religiosa y lingüística. El 23 trata de la igualdad entre hombres y mujeres en todos los ámbitos. Sin embargo, se dispone que el "principio de la igualdad no impide el mantenimiento o la adopción de medidas que prevean ventajas especiales a favor de un sexo menos representado". El 24 se refiere a los derechos del niño, entre los que incluye el de "expresarse libremente", en función de su "edad y madurez". Los artículos 25 y 26 son de gran interés. Se refieren a las personas mayores" (de tercera edad), que tienen "derecho a una vida digna e independiente y a participar en la vida social y cultural (artículo 25) y a las personas discapacitadas, que deben beneficiarse" de medidas dirigidas a asegurarles su autonomía, su integración social y profesional y su participación en la vida de la comunidad" (artículo 26). El capítulo IV se titula "Solidaridad". Es imposible intentar resumir los once artículos (27 a 38) de este capítulo. Pero hay que recordar que bajo la denominación de "solidaridad", incluye una materia muy diversa y la enunciación de derechos de diferente naturaleza y caracterización jurídica. Están, así, enunciados derechos de típico contenido social, o que a veces han sido denominados de la segunda generación, ${ }^{30}$ otros de los cuales se encuentran enunciados en otros capí-

30 Gros Espiell, Héctor, Los derechos económicos, sociales y culturales; su protección y promoción internacionales, Washington, OEA, 1984; Gros Espiell, Héctor, "Los derechos culturales 
tulos de la carta, junto con derechos de posterior individualización jurídica, que también alguna doctrina ha llamado, de la tercera generación, ${ }^{31}$ sin perjuicio de la existencia de otras denominaciones.

Lo interesante es recordar que todos estos derechos se engloban, creo que parcialmente con razón, bajo el título común de "Solidaridad", expresión que en ciertas ocasiones ha sido utilizada para referirse a algunos de los "nuevos derechos" 32 de los individualizados, como de la tercera generación y que en otras ocasiones han sido tipificadas como "derecho de vocación comunitario". ${ }^{33}$ Pero este criterio debe ser relativizado con la consideración de que todos los derechos humanos, todos los derechos fundamentales, requieren la solidaridad y se integran necesariamente con ella — aunque quizás en distinto grado y forma - para configurarse plenamente en su conceptualización jurídica y en su eficacia y aplicación real.

Por lo demás, es esencial tener en cuenta que al incluir estos artículos, enunciados en el capítulo IV entre los "derechos fundamentales", la carta, certeramente, les atribuye el carácter de verdaderos derechos y no como ha sostenido algún erróneo criterio político gubernamental, de nuevas aspiraciones u objetivos sociales.

A estas posiciones es necesario agregar que tal como está redactada la carta, reconoce y afirma que todos los derechos fundamentales se relacionan y se condicionan recíprocamente siendo interdependientes entre sí.

en cuanto derechos humanos", Revista Uruguaya de Derecho Constitucional y Político, Montevideo, núm. 92, 1994; M’baye, Kéba, "Tensión Droits Civils et Droits Economique, Sociaux et Culturals", en varios autores, Droits international, bitan et perspectives (Red. Gen. M. Bedjaoui), París, Pedone-Unesco, 1991, p. 1119-1122; Jacquart, Michele, "Droits economiques, sociaux et culturals", en varios autores, Droits internacional..., op. cit, en esta misma nota, cap. XLIX, pp. 1153-1173.

31 Vasak, Karel, "Pour une troisième gènèration des droits de l'homme", Etudes et essais en l'honneur de Jean Pictel, La Haya, Genéve, 1984; id., "Revisiter la troisième gènèration des droits de l'homme avant leur codification", en Gros Espiell, Héctor, Amicorum liber, Bruxelles, Bruylant, 1997, vol. II, pp. 1649-1679; Meyer Bisch, Patrice, "D’une succession de générations à un système des droits de l'homme", en Vasak, Karel, Amicorum liber, cit., en esta misma nota; Uribe Vargas, Diego, "Karel Vasak y la tercera generación de derechos humanos", en Vasak, Karel, Amicorum Liber, cit., en esta misma nota; Youssoufi, Abderihmane, "Réflixions sur l'Apport de la 'Troisième génération des Droits de l'Homme'", en Vasak, Karel, Amicorum Liber, cit., en esta misma nota.

32 Carpizo, Jorge, "Los nuevos derechos humanos", Le Monde Diplomatique (ed. española), México, mayo de 1985.

33 Bedjaoui, Mohamed (red. gral.), Droit international, bilan et perspectives, t. 2, tit. II: Les Droits a Vocation Communitaire, introd. de Héctor Gros Espiell, París, Pedone-Unesco, pp. 1237-1247. 
Tratan estos once artículos del derecho a la información y a la consulta a los trabajadores en el seno de la empresa (artículo 27), a la negociación y acción colectiva (artículo 28), a los servicios de colocación (artículo 29), a la protección contra el despido injustificado (artículo 30), a las condiciones de trabajo justas y equitativas (artículo 31), a la prohibición del trabajo de los menores y a la protección del de los jóvenes (artículo 32), a la vida familiar y profesional (artículo 33), a la seguridad social y a la asistencia social (artículo 34), a la protección de la salud (artículo 35), y al acceso a los servicios de interés económico general dirigidos "a promover la cohesión social y territorial de la Unión” (artículo 36). Los dos últimos artículos de este capítulo, se refieren a la protección del medio ambiente (artículo 37), "según el principio" del "desarrollo sostenible" y a la protección de los consumidores (artículo 38). El capítulo V trata de la "Ciudadanía". Comienza con el derecho de los ciudadanos de la unión a ser electores y elegibles en las elecciones del Parlamento Europeo y en las elecciones municipales en el Estado miembro en que resida, (artículos 39 y 40). Incluye el derecho a "una buena administración" (artículo 41). Hay que destacar el "Derecho de acceso a los documentos", reconocido a todas las personas físicas o morales residentes o con sede en un Estado miembro de la unión, a los documentos del Parlamento Europeo, del consejo y de la comisión (artículo 42). El derecho a someter al defensor del pueblo de la unión, es decir al Ombudsman comunitario (artículo 43), los casos de mala administración, en la acción de las instituciones u órganos comunitarios, con exclusión de la materia jurisdiccional. El derecho de petición (artículo 44), el de circulación y residencia, reconocido a todo ciudadano de la unión (artículo 45) y el derecho a la protección diplomática y consular de todo ciudadano de la unión, en un tercer país en el cual el país del cual es ciudadano no esté representado (artículo 46).

Este capítulo VI se titula "Justicia". Este capítulo contiene cuatro artículos (47 a 50).Se refieren al derecho a la tutela judicial efectiva y a un juez imparcial (artículo 47), a la presunción de inocencia y al derecho a defensa (artículo 48), al principio de legalidad y de proporcionalidad de los delitos y las penas (artículo 49) y al derecho a no ser acusado o condenado dos veces por el mismo delito (artículo 50).

El capítulo VII (Disposiciones generales ) comienza con lo relativo al ámbito de aplicación de la carta, de acuerdo con el principio de subsidiariedad (artículo 51). Interesa especialmente destacar el artículo 52 referente a las eventuales limitaciones, de los derechos y las libertades re- 
conocidas en la carta, que deben siempre resultar de "la ley y respetar el contenido esencial de los derechos, deberes y libertades" y el artículo 53 ("nivel de protección"), que establece el principio que la carta no podrá interpretarse como limitadora de los derechos humanos reconocidos en el derecho internacional o en las Constituciones de los Estados miembros.

Por último, bajo el título de "Prohibición del abuso de derecho", el artículo 54 dispone que la carta no podrá interpretarse en el sentido que implique un derecho cualquiera a dedicarse a una actividad o a realizar un acto tendente a la destrucción de los derechos o libertades reconocidos en la presente carta o a limitaciones más amplias de estos derechos y libertades que las previstas en la carta.

10. La carta no posee un sistema de aplicación propio y autónomo. Esto es la consecuencia de su actual naturaleza jurídica. Sin perjuicio de sus efectos como "texto de inspiración y referencia" — efectos ya reconocidos por la jurisprudencia europea-, su aplicación podrá eventualmente ser hecha por el Tribunal de Justicia de Luxemburgo de la Unión Europea o, incluso, por la Corte Europea de Derechos Humanos de Estrasburgo del Consejo de Europa.

La cuestión cambiará cuando pase a ser la parte II de la futura Constitución Europea, porque entonces la aplicación de la carta estará asegurada en la misma forma, por los mismos órganos y con la misma fuerza, que todo el resto de la Constitución.

11. ¿Cuál es hoy la naturaleza jurídica de la carta? ¿Cuál es el efecto de este instrumento internacional? ¿Cuál es su incidencia sobre los sistemas constitucionales de los países miembros de la Unión Europea? Todas estas preguntas se refieren a lo que la carta es hoy. Pero además es ineludible encarar la cuestión de lo que la carta será, o de lo que significará, cuando entre en vigencia la proyectada Constitución Europea.

12. Empecemos por analizar la significación actual de la carta. La Carta Europea de Derechos Fundamentales no es un tratado. Por tanto, $a$ priori, su naturaleza jurídica es distinta de la Convención Europea para la Protección de los Derechos Humanos y de las Libertades Fundamentales del Consejo de Europa y de la Carta Social de Europa. ${ }^{34}$

34 Gros Espiell, Héctor, La Convention Européenne et la Convention Americaine, cit., Academie de Droit International, Recueil de Cours, t. 218, pp. 181-183; Sanz Moreno, Raquel, "Derechos humanos y Unión Europea", Revista de Derecho Público, Montevideo, Fundación de Cultura Universitaria, núm. 21-22, 2002. 
Carece, por tanto, la carta de la fuerza jurídica directa que tendría si constituyera un tratado internacional. Como ha dicho Robert Badinter ella constituye hoy "un texto de inspiración y de referencia". ${ }^{35}$

Cuando fue elaborada se encaró la posibilidad de que llegara a constituir una convención multilateral, uno de los instrumentos de los que resultan "las obligaciones internacionales comunes a los Estados miembros, el Tratado de la Unión Europea y los Tratados Comunitarios". Pero esta idea inicial se frustró no sólo por problemas y dificultades jurídicas, sino también por razones políticas circunstanciales.

13. Teniendo en cuenta el principio de la subsidiariedad, la carta reafirma los derechos humanos reconocidos en los tratados internacionales de que son parte los Estados miembros de la unión, especialmente los de carácter regional europeo y en particular la Convención Europea para la Protección de los Derechos Humanos y las Libertades Fundamentales y la Carta Social Europea, ambos instrumentos pertenecientes al sistema del Consejo de Europa. Todo esto se encuentra expresado y reconocido en el preámbulo de la Carta de Derechos Fundamentales de la unión. De tal modo la Carta de Derechos Fundamentales de la Unión Europea se integra con el reconocimiento de los derechos humanos proclamados y garantizados por el derecho internacional convencional, específicamente con el que resulta de las convenciones del Consejo de Europa.

Pese a la distinta naturaleza jurídica de la carta y de estos tratados, se produce como consecuencia de su coexistencia, en materia de derechos humanos, una acción recíproca entre los sistemas jurídicos de la Unión Europea y del Consejo de Europa, una suma de derechos y garantías y una recepción de fórmulas protectoras y de soluciones jurisprudenciales, en beneficio de los ciudadanos y de quienes viven en la Unión Europea.

14. El efecto que hoy tiene la Carta de los Derechos Fundamentales en Europa, con respecto a la Unión Europea y de sus Estados miembros deriva naturalmente de su naturaleza jurídica actual.

Pero sin perjuicio de las limitaciones que de ello resultan, no puede desconocerse que como texto que sirve "de inspiración y de referencia", ha incidido e incide, no sólo en la política general de la Unión Europea en materia de derechos humanos, sino también en la interpretación de las normas constitucionales internas y en la recepción de nuevos conceptos 
en cuanto a los derechos fundamentales, hecha en especial por los tribunales constitucionales de algunos países miembros de la unión. ${ }^{36}$

No es del caso analizar ahora cada uno de esos aportes jurisprudenciales. Únicamente queremos destacar este extremo y recordar que algo parecido empezó a ocurrir en los años posteriores a 1948 con la Declaración Universal de Derechos Humanos, cuando comenzó a ser citada por algunos tribunales nacionales como guía e inspiración para los derechos nacionales, antes de que su valor propio como fuente de derecho, fuera reconocido por la Corte Internacional de Justicia, por la doctrina y por las conferencias internacionales de derechos humanos de Teherán (1969) y Viena (1994). ${ }^{37}$

15. La carta llegará a ser parte de la futura Constitución Europea. En efecto ella constituirá "la segunda parte de la presente Constitución", según lo que dispone el párrafo 1 del artículo I-7 del título II, que asimismo expresa: "La unión reconoce los derechos, libertades y principios enunciados en la Carta de los Derechos Fundamentales".

Con una redacción distinta, la fórmula adoptada en el proyecto de Constitución es una expresión de la misma idea contenida en el proyecto de Robert Bandinter, cuyo artículo 3 expresaba: "L'Union considère la Charte des droits fundamentaux comme partie intégrante de la Constitution". 38

En su libro, Badinter, justificando este texto, ha dicho con razón: "Toute Constitution contemporaire s'ouvre par una Déclaration des droits fundamentaux. La Charte deviendra dans la declaration de Droits de l'homme de l'Union, et ses dispositions auront alors valeur constitutionale". ${ }^{39}$

En efecto, como ya he dicho precedentemente, cuando la carta esté integrada en la futura Constitución Europea, será parte de la misma, su

36 Celeotto, Alfonso, "Carta dei Diritti Fondamentali e Constituzione Italiana: Verso il 'Tratado Constituzionale Europeo'”, en Asociación Argentina de Derecho Constitucional, Debates de Actualidad, Buenos Aires, año XVIII, núm. 189, oct. 2002-marzo 2003, pp. 133-141; Scala, "L'Emergere della Carta dei Diritti Fondamentali dell'Unione Europea nella Giuridprudenza", Giurisprudenza Italiana, 2002; Santini, "Dirito ad una Buona Amministrazione: La Prima Applicazione della Carta dei Diritti Fondamentale dell'Unione Europea", Giurisprudenza Italiana, 2002.

37 Gros Espiell, Héctor, "Les Droits de l'Homme et la Cour Internationale de Justice; Une Vision Latino-Americaine", Liber Amicorum Judge Shigeru Oda, Londres, Nueva York, Kluwer Law International, The Hague, 2002, vol. II, pp. 1449-1469.

38 Badinter, Robert, op. cit., nota 13, p. 20.

39 Ibidem, p. 49. 
contenido será materia constitucional y su aplicación se hará efectiva y será garantizada por los mismos órganos y con la misma fuerza que todo el resto de la normativa de la Constitución de Europa.

\section{UNA VISIÓN IBEROAMERICANA DE LA CONSTITUCIÓN Y DE LA CARTA}

La visión de la significación de la Carta Europea de Derechos Fundamentales y del proceso de elaboración de la futura Constitución de Europa, no puede ser igual para un europeo que para un iberoamericano.

Para el primero, sujeto de la aplicación de la carta, ésta incide ya hoy en la situación de los derechos humanos en el ámbito geográfico en el que él habita y en la comunidad humana en la que él vive y que se relaciona directamente con las situaciones constitucionales de los Estados miembros de la Unión Europea, de uno de los cuales él es nacional además de ser un ciudadano de la unión. Para el primero, para el habitante de Europa, además, la futura Constitución Europea será el texto bajo el cual habrá de vivir, que se sumará al de su propia Constitución nacional, instrumento aquél de nueva naturaleza, que regulará la existencia y el accionar de una Europa unificada y unida, bajo una inédita y trascendente forma institucional.

Cuando la carta forme parte de la Constitución también será diferente la apreciación europea de la iberoamericana.

Para un iberoamericano, que contempla y analiza la cuestión desde fuera de Europa, y al que no se aplica hoy la carta y al que tampoco se le aplicará mañana esta carta ni la Constitución futura de Europa, el tema le interesa y le atrae por el significado de la evolución de que éstos dos instrumentos - uno actual y otro futuro - son expresión. Le atrae y le interesa como muestra de lo que ocurre en Europa, de las enseñanzas a extraer de esa experiencia y como elemento de reflexión comparativo - político y jurídico-, sobre la situación actual de América Latina y sus perspectivas futuras.

Pero además, el tema — para ambos, para el iberoamericano y para el europeo- presenta un interés muy grande en cuanto a lo que es $-\mathrm{y}$ lo que será- el límite siempre impreciso, movedizo, cambiante y evoluti- 
vo, entre el derecho internacional y el derecho interno y la ubicación del derecho comunitario frente a esta cuestión. ${ }^{40}$

El asunto genera, asimismo, reflexiones sobre la aparición en Europa - y quizás el desarrollo, en el mañana, en otros ámbitos geográficos-, de realidades políticas y de formas político-sociales, que sin ser estrictamente de derecho interno, contienen elementos de analogía - y de diferencia también - con la idea tradicional de confederación. ${ }^{41}$ Son modelos que quizás, en sentido muy amplio y con elementos de diversidad con los modelos tradicionales, podrían calificarse de confederación.

Son estos aspectos, derivados de la consideración del tema de la futura Constitución Europea y de la actual Carta de Derechos Fundamentales de la Unión Europea, los que pienso que generan hoy, especialmente, el interés de los iberoamericanos.

Es un interés análogo con el que provoca en los europeos. Pero que al mismo tiempo contiene elementos diferenciales, con los que este gran momento que vive el pensamiento político jurídico constitucional, nacional e internacional, genera en los ciudadanos de Europa.

40 En mi estudio, "Los derechos humanos. Tendencias actuales y previsibles del constitucionalismo", en varios autores, Constitución y constitucionalismo hoy, cincuentenario del derecho constitucional comparado de Manuel García Pelayo, Caracas, 2001, pp. 298 y 299, he dicho a este respecto: "En su Derecho constitucional comparado, Manuel García Pelayo destacó la relatividad histórica del contenido específico del derecho constitucional y señaló que "no es un categoría eterna". La idea tradicional de que existía un ámbito o un espacio propio del derecho interno y otro totalmente diferente del derecho de gentes, cada uno de los cuales contenía una materia distinta, hace años que ha perdido total validez y significación. Hoy se comprende y se sabe que los límites de los dos derechos son imprecisos, cambiantes y evolutivos, y que hay temas - y en los procesos de cambio previsible de la historia sin fin, habrá en el mañana otros muchos- que están en la materia de ambos".

41 ¿Federación de Estados Naciones (Jacques Delors), Federación de Estados Europeos (Robert Badinter) o Confederación? Véase Le Fur, Louis, Etat Federal et Confederation d'Etats, París, 1896: de permanente utilidad por la profundidad de su análisis y su perspectiva histórica; como lo ha puesto de manifiesto, con un enfoque actual Leben, Charles, Avant Propos, ed. facs., París, Librairie Générale de Droit et de Jurisprudence, 2000; La Pérgola, Antonio, "La Confederación", en varios autores, Los nuevos senderos del federalismo, Madrid, 1994; López Aguilar, Juan Fernando, "Constitución y Federación europea. Conversación con el profesor Antonio La Pérgola", Anuario de Derecho Constitucional y Parlamentario, núm. 14, Asamblea Regional de Murcia, Universidad de Murcia, 2002. 